\title{
Trace Element Concentration in São Francisco River Water Using STXRF and PIXE Techniques
}

\author{
F. R. Espinoza-Quiñones, S. M. Palacio, R. M. Galante, F. L. Rossi, D. C. Zenatti, \\ I. R. A. Pereira, R. A. Welter, N. Rossi, C. L. Obregón, J. M. T. de Abreu, \\ Núcleo de Biotecnologia e Desenvolvimento de Processos Químicos - NBQ, \\ Universidade Estadual do Oeste do Paraná-UNIOESTE/Campus de Toledo, PR, Brasil
}

M. A. Rizzutto, N. Added, and M. H. Tabacniks

Instituto de Física, Universidade de São Paulo, São Paulo, SP, Brasil

Received on 9 June, 2005

\begin{abstract}
Trace element concentrations in water from São Francisco River using Particle Induced X-ray Emission (PIXE) and Synchroton Total Reflection X-ray Fluorescence (STXRF) techniques are measured. The main objective of this work was to characterize and to monitor the trace elements in the water of São Francisco River, as well as to provide valuable information about the levels of metallic ions pollutants. Water samples were collected monthly at five locations along the course of the river from July 2003 to April 2004. As an internal standard, $11.6 \mathrm{ppm}$ of Yttrium was added to $10 \mathrm{ml}$ of the water sample. The PIXE and TXRF measurements were performed at the Ion Beams and Materials Laboratory (LAMFI) and the Brazilian National Synchrotron Light Laboratory (LNLS), using a proton beam and a polychromatic X-ray beam, respectively. $\mathrm{Si}(\mathrm{Li})$ detectors were used to collect the X-ray spectra. Due to the excellent detection limits of the PIXE and STXRF analysis, up to 15 elements were quantified. The highest total content of $\mathrm{Cr}, \mathrm{As}, \mathrm{Cu}$ and $\mathrm{Zn}$ detected in river water are above the limits recommended by the environmental legislation.
\end{abstract}

\section{INTRODUCTION}

The search and identification of trace elements in the environment is an important field of modern science. The growing interest about trace elements in biological materials is just another indicator of the needs in modern biological and environmental science. It is recognized that the trace elements diversity is essential for life and great effort is being made to understand its actions. It is known that low trace elements are essential for life, yet in excess they may also be toxic [1].

During the last two decades, there has been considerable development in the sampling and analytical techniques for the measurement of trace elements in the environment. Ion Beam Analysis (IBA) methods and X-ray Fluorescence (XRF) with its as Total Reflection XRF, TXRF, and Synchrotron Total Reflection XRF, STXRF, have been shown to be powerful methods for measuring trace element content in soils, sediments, water and air particulates [2, 3]. These techniques have the advantage of speed, sensitivity, simplicity, and the ability to analyze mixtures without prior treatment or separation. In this work, water samples from the São Francisco River were analyzed for trace elements at the X-ray fluorescence beam line installed at the $2.5-\mathrm{GeV}$ Brazilian Synchrotron Light Source [4-7].

\section{MATERIALS AND METHODS}

\section{A. Sample collection locations}

The São Francisco river hydrographic basin is located in the southern region of Brazil in the western part of the State of Paran and drains an area of approximately $2200 \mathrm{~km}^{2}$ over an extension of $150 \mathrm{~km}$.

Five sampling sites were installed along the river stream in order to monitor systematically the levels of heavy metals and identify potential pollution sources in the freshwater ecosystem of the São Francisco basin. The sampling sites 1 and 2 are located before and after the point where Antas river reaches the São Francisco river, respectively. A protocol was set up for monthly collection of water samples and for measuring heavy metal concentrations. A map of the area under investigation with the localization of the sampling sites is shown in Figure 1.

A total number of 60 water samples were collected from July 2003 to April 2004.

\section{B. Target Preparation}

Standard stock solution $\left(11.6 \times 10^{3} \mathrm{mg} \mathrm{l}^{-1}\right)$ of yttrium was prepared dissolving quantitatively a $50 \mathrm{~g}$ Merck package $\mathrm{Y}\left(\mathrm{NO}_{3}\right)_{3.6} \mathrm{H}_{2} \mathrm{O}$ in Ultra Pure Milli-Q water. The solution was stored in an acid-washed volumetric flask. A $10 \mu l$ of yttrium stock solution was added in an aliquot of $10 \mathrm{ml}$ of each sample. A $5 \mu l$ from the resulting solution was pipetted on $2.5 \mu \mathrm{m}$ thick kimfol $\left(\mathrm{C}_{16} \mathrm{H}_{14} \mathrm{O}_{3}\right)$ stretched on plastic rings $(\phi 25 \mathrm{~mm}$ and $2 \mathrm{~mm}$ thick), and $3 \mathrm{~mm}$ thick acrylic disks, and left to dry at ambient temperature in a clean box.

The sampling, drying, and thin target preparation processes for river water and standard samples were identical [8]. 


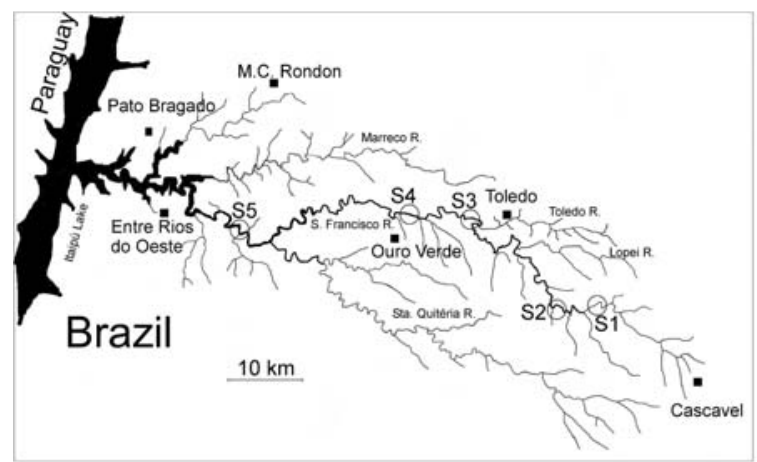

FIG. 1: Map of São Francisco hydrological basin showing the location of the five sampling sites.

\section{Instrumentation}

The PIXE measurements using a $2.39 \mathrm{MeV}$ proton beam were done at the Ion Beams and Materials Laboratory (LAMFI) of the Physics Institute of the University of São Paulo [9]. Typical beam currents, of few nA, were used to reduce dead time and signal pile-up. The X-rays were recorded using two $\mathrm{Si}(\mathrm{Li})$ detector with FWHM resolution of about $145 \mathrm{eV} \mathrm{MnK} \alpha$ placed at $120^{\circ}$ and $90^{\circ}$ to the beam direction.

The STXRF measurements were carried out using the polychromatic X-ray beam, with maximum energy of $20 \mathrm{keV}$, of the XRF line, at the National Laboratory of Synchrotron Light (LNLS), located in Campinas-SP [4]. A Si(Li) detector, with $160 \mathrm{eV}$ FWHM Mn-K $\alpha$ line, surrounded by tantalum collimators and placed at $90^{\circ}$ to the incident beam, was used for $\mathrm{X}$-Ray detection.

For both techniques, the X-ray spectra were analyzed using the AXIL program [10].

\section{Quantitative analysis by PIXE and STXRF}

In the PIXE technique, the effective yield of the $\mathrm{K}$ and $\mathrm{L} \mathrm{X}$ ray series were performed using a set of calibrated thin films from Micromatter Co. USA. To determine the elemental sensitivity curve of the STXRF system, several single element standard solutions with atomic number in the range of interest were prepared with well-defined concentrations ranging (from 1 to $10 \mu g \mathrm{ml}^{-1}$ ). All standard solutions were spiked with the same amount of Yttrium solution as well as the water samples.

\section{RESULTS}

Typical X-ray spectra for STXRF and PIXE obtained from river water samples are shown in Figure 2, with prominent peaks for the $\mathrm{K}$ X-ray lines of $\mathrm{K}, \mathrm{Ca}, \mathrm{Cr}, \mathrm{Mn}, \mathrm{Fe}, \mathrm{Ni}, \mathrm{Cu}, \mathrm{Zn}$ and
$\mathrm{Y}$, the internal standard element. Backgrounds were subtracted in the $K_{\alpha}$ areas that were used to calculate the elements concentrations of the samples.

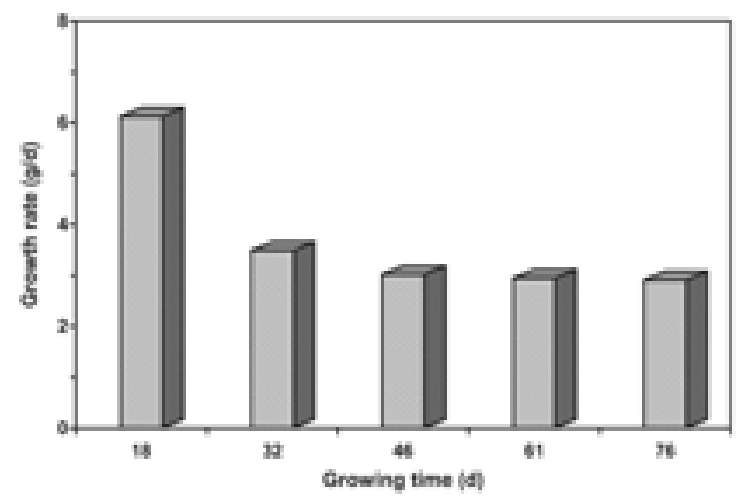

FIG. 2: Comparison of the TXRF and PIXE spectra for the same water sample on acrylic disk and Kimfoil.

The relative elements concentrations were calculated using the following relation [6].

$$
C_{Z}=\frac{I_{Z}}{I_{S}} \frac{Y_{S}}{Y_{Z}} C_{S}
$$

where $Y_{S} / Y_{Z}$ is a ratio derived from effective yield curve, $I_{S} / I_{Z}$ is a ratio representing the relative-to-Yttrium fluorescence intensity of the element, $C_{Z}$ is the element concentration ( $\mu g$ $\left.m l^{-1}\right)$, and $C_{S}$ is the Yttrium internal standard concentration

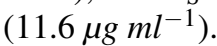

The minimum limit of detection criterion of $3 \sqrt{B G}$, where $\mathrm{BG}$ is the number of counts of the background under the peak, was adopted. As shown in Figure 3, the minimum detection limits for the TXRF and PIXE techniques down to $1 n g m l^{-1}$ $(\mathrm{ppb})$ were achieved around the iron element.

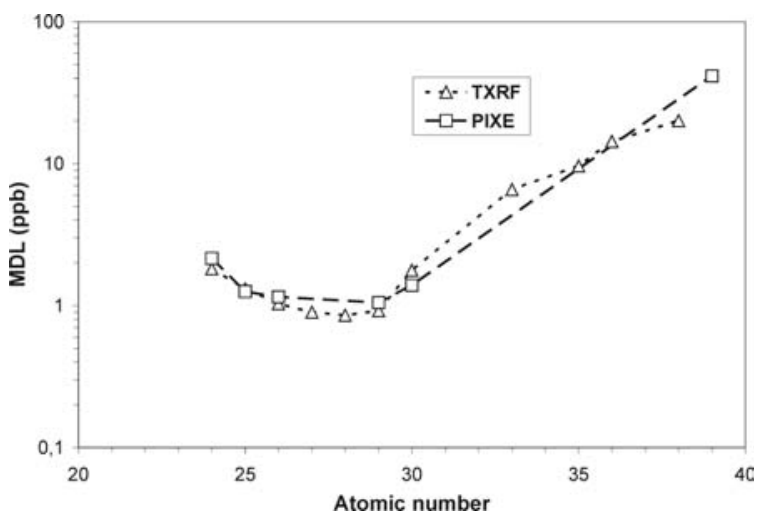

FIG. 3: Curve of the Minimum Detection Limit for TXRF and PIXE techniques.

Due to the excellent detection limits of the TXRF and PIXE up to 15 elements were identified in the samples. The mean 
concentration values for the macro elements such as $\mathrm{K}, \mathrm{Ca}$, $\mathrm{Ti}$ and $\mathrm{Fe}$ and for the trace elements $\mathrm{Br}$ and $\mathrm{Sr}$ were summarized in Figure 4, which compares the average trace element concentrations at all stations.

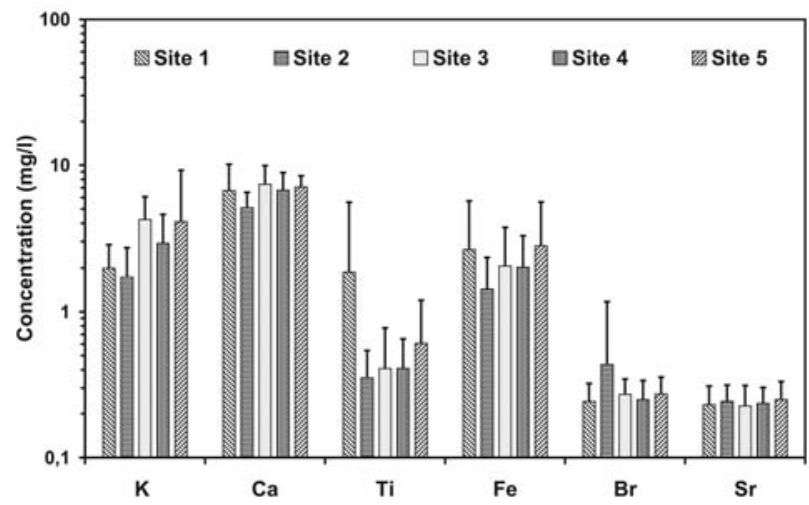

FIG. 4: Mean $( \pm \mathrm{SD})$ concentration values (in $m g / l)$ for the macro elements $\mathrm{K}, \mathrm{Ca}, \mathrm{Ti}$ and $\mathrm{Fe}$ and the trace elements $\mathrm{Br}$ and $\mathrm{Sr}$, obtained in the five sampling sites.

\section{DISCUSSION}

It can be seen from Figure 5 that the concentrations of total copper in river water at all sites are much higher than the 20 ppb recommended by the Brazilian environmental legislation [11] for river water class II. Except for $\mathrm{Cu}$, all other elements show average concentrations below the allowed limits. However, at some sites, the upper limits of $\mathrm{Cr}, \mathrm{Zn}$, and As are above the allowed limits. This is certainly a matter of concern which indicates urgent need to start controlling pollution sources to avoid future problems.

Concentration values of zinc exhibited significant increase at sites 3, 4 and 5, above the $180 \mathrm{ppb}$ recommended by the Brazilian legislation. The highest value of zinc was found in site 1 . This may be attributed to anthropogenic sources from the Cascavel city.

It was observed that the highest chromium concentration at site 5 has reached $100 \mathrm{ppb}$, which is two times the maximum permissible concentration in drinking water, recommended by the World Health Organization [12] and the Brazilian Environmental Legislation [11] for the hexavalent form in river water. This contaminant could be an industrial effluent from the tanneries located after the site 3 near to Toledo city.

At sites 1 and 3, the upper limits of arsenic are much higher than the $50 \mathrm{ppb}$ recommended by the Brazilian legislation.
The highest values of arsenic were found at sampling site 3 which is downstream the ending of Toledo river, receiving the addition of partially untreated urban and industrial effluents from Toledo city. This element may also be associated with the run-off from agricultural lands located into the Toledo and Lopei river basins.

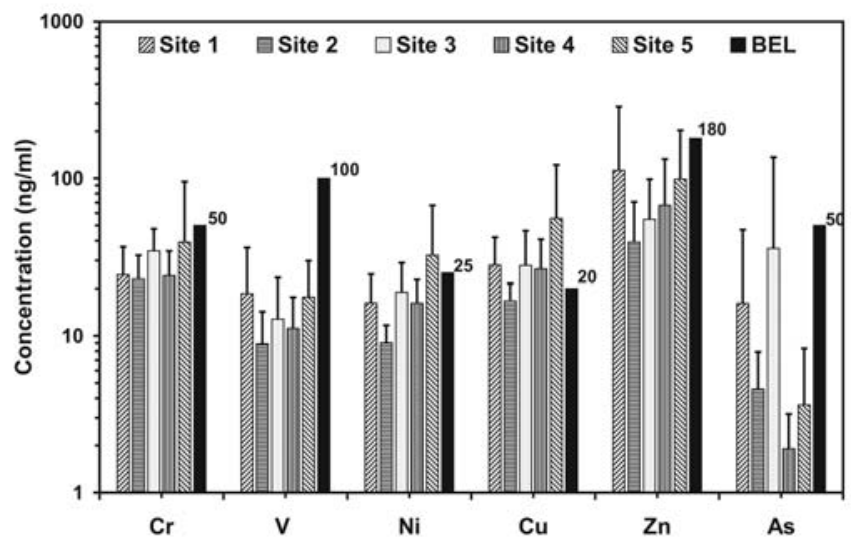

FIG. 5: Mean $( \pm \mathrm{SD})$ concentration values (in $n g / m l)$ for $\mathrm{Cr}, \mathrm{V}$, $\mathrm{Ni}, \mathrm{Cu}, \mathrm{Zn}$ and $\mathrm{As}$, obtained in the five sampling sites compared to the limit recommended by the Brazilian Environmental Legislation (BEL).

\section{CONCLUSION}

The present work is the first attempt to identify trace elements in the São Francisco River of the Brazilian state of Paraná. The main metallic pollutants detected in São Francisco River water were $\mathrm{Cu}$ and $\mathrm{Cr}$. The highest total content of these metallic pollutant was found in site 5 located next to the ending of São Francisco River. A major portion of $\mathrm{Cr}$ pollutant is believed to come from tanneries discharges into the São Francisco river. The occurrence of cromium above the prescribed limits indicates the necessity of improve techniques for industrial waste treatment. Because metals tend to accumulate in the river sediment, plants and fishes, investigations of trace elements in these ecosystems are also in progress.

\section{Acknowledgments}

We thank LNLS (Laboratório Nacional de Luz Síncrotron) for financial support of the D09-XRF 1979 and 2240 projects. The Environmental Research Group of Western Parana State University is grateful to LAMFI staff for operating the accelerator. The authors MAR, NA, MHT thank to FAPESP and $\mathrm{CNPq}$ for financial support.

224 (1997).

[2] R. Van Grieken, and A. A. Markowicz, Handbook of X-ray
[1] P. A. Amundesen, F. J. Staldvik, A. A. Lukin, N. A. Kashulin, O. A. Popova, and Y. S. Reshetnikov, Sci. Total Environ. 201, 
Spectrometry, Marcel Dekker, New York (1993).

[3] K. G. Malmqvist, Nucl. Instr. and Meth. B85, 84 (1994).

[4] C. A. Perez, M. Radtke, H. J. Sanchez, H. Tolentino, R. Neuenshwander, W. Barg, M. Rubio, M. I. S. Bueno, I. M. Raimundo, and J. R. Rohwedder, Synchrotron Radiation: Beam line Instrumentation and Experiments, X-Ray Spectrometry 28, 320 (1999).

[5] K. P. Koutsenogii, SRXRF in Ecology, Nucl Instr. and Meth. A448, 425 (2000).

[6] K. Baur, S. Brennan, D. Werho, L. Moro, and P. Pianetta, Recent Advances and Perspectives in Synchrotron Radiation TXRF Nucl. Instr. and Meth. A467-468, 1198 (2001).

[7] R. Klockemkamper, and A. Von Bohlen, Elemental Analysis of Environmental Samples by Total Reflection Fluorescence: a
Review, X-ray Spectrometry 25, 156 (1996).

[8] S. M. Simabuco, and E. Matsumoto, Synchrotron radiation total reflection for rainwater analysis Spectrochimica Acta B 55, 1173 (2000).

[9] M. H. Tabacniks, University of São Paulo, Physics Institute Report 1469, 50 (2000).

[10] P. Van Espen, K. Janssens, and I. Swenter, AXIL X-Ray Analysis software, Canberra Packard, Benelux.

[11] Conselho Nacional do Meio Ambiente (CONAMA), Resolução no. 20, Ministério do Desenvolvimento Urbano e Meio Ambiente, Brasilia, (1986).

[12] World Health Organization Guidelines for Drinking-water Quality, chapter 8, WHO, Geneva, (2003). 